\title{
Enzyme-Catalyzed Production and Chemical Composition of Diacylglycerols from Corn Oil Deodorizer Distillate
}

\begin{abstract}
Diacylglycerols (DAG) were enzymatically synthesized by lipase-catalyzed esterification of glycerol with fatty acids from corn oil deodorizer distillate (CrODD). Effects of reaction parameters such as reaction time, temperature, enzyme type, enzyme load, substrate mole ratio, and water content, as well as the effect of molecular sieves as a water adsorbent were investigated. Rhizomucor miehei lipase (Lipozyme RM IM) was found to be most effective among the lipases screened. The following conditions yielded $70.0 \%(\mathrm{w} / \mathrm{w})$ DAG: $5 \mathrm{~h}$ reaction time, $65^{\circ} \mathrm{C}$ reaction temperature, $10 \%$ (w/w) Lipozyme RM IM, 2.5:1 fatty acid to glycerol molar ratio, and 30\% (w/w) molecular sieves. DAG synthesis of $12.4 \%(\mathrm{w} / \mathrm{w})$ was still observed at $10 \%(\mathrm{w} / \mathrm{w})$ water content. $84.2 \%(\mathrm{w} / \mathrm{w})$ of DAG was obtained after purification. The DAG oil comprised predominantly of 1-oleoyl-3-linoleoyl-glycerol (28.5\%), 1,3-diolein (22.7\%), 1-oleoyl-2-linoleoyl-glycerol (17.9\%), and 1,2-diolein (10.9\%). Fatty acid profile was similar to that of refined, bleached and deodorised (RBD) corn oil. The ratio of 1,3- to 1,2-positional isomers of DAG was at 1.82:1.
\end{abstract}

Keyword: Corn oil, Deodoriser distillate, Diacylglycerol, Enzymatic synthesis, Esterification, Lipase, Lipozyme RM IM, Rhizomucor miehei 